\title{
Hugo Salazar Valdés: una poética olvidada ${ }^{58}$ Hugo Salazar Valdés: Forgotten Poetry
}

\author{
Fabio Martínez \\ Recibido: 3 de Marzo 2011. Aprobado: 18 de Abril de 2011
}

\begin{abstract}
Resumen
Este ensayo presenta al poeta Hugo Salazar Valdés como un escritor de conocimiento obligatorio para construir el panorama de la poesía colombiana y latinoamericana. Su particularidad como escritor se adjudica a dos hechos fundamentales que son claves en el destino de todo poeta: la región que lo vio nacer: el Chocó, el litoral recóndito y la época que tuvo que vivir: las décadas del treinta y cuarenta, una época signada por las ideas liberales del país; determinada por un país dependiente y atrasado que iba larvando en su interior el signo fatídico de la violencia, producto de las desigualdades sociales y de las exclusiones regionales y raciales.
\end{abstract}

Palabras clave: Hugo Salazar Valdés; Poesía afrocolombiana; Poesía latinoamericana.

\begin{abstract}
This essay presents the poet Hugo Salazar Valdes as a writer of mandatory knowledge to build the panorama of Colombian and Latin American poetry. Its uniqueness as a writer is awarded to two fundamental facts that are key to the fate of every poet: the region where he was born: the Chocó, the hidden littoral and the time he had to live: the thirties and forties, a time marked by the liberal ideas of the country, and determined by a dependent backward country that was forging inside the fateful sign of violence, a product of social inequalities and regional and racial exclusions.
\end{abstract}

Keywords: hugo Salazar Valdés; Afrocolombian poetry; Latin American poetry.

Conocí a Hugo Salazar Valdés cuando a finales de 1960, cursaba mis estudios de bachillerato en el Instituto Politécnico Municipal. El colegio, que estaba situado en una antigua fortaleza militar sobre el Paseo Bolívar de Santiago de Cali -hoy destruida por la mano del hombre-, se jactó durante esos seis largos y tediosos años académicos de tener entre sus profesores a tres escritores de la Región que se ocupaban en aquel entonces de la enseñanza del Español y la Literatura: el escritor y periodista de Sevilla, Valle, Lino Gil Jaramillo, el poeta de Supía, Caldas, Gilberto Garrido, y el poeta de Condoto, Chocó, Hugo Salazar Valdés.

El más conocido de los tres bardos era Lino Gil Jaramillo, que cada domingo lo veíamos en las páginas de El País y El Espectador con su melena revuelta, su pipa de caoba y su impecable vestido

\footnotetext{
${ }^{58}$ Artículo derivado del proyecto de investigación Biblioteca Afrocolombiana, patrocinado por el Ministerio de Cultura de Colombia, del cual el autor hizo parte en la preparación, organización y estudio de la poesía del escritor chocoano Hugo Salazar Valdés.
} 
entero. El más desconocido era Hugo Salazar Valdés, que como Lino Gil, vestía de una manera pulcra e intachable con la pequeña diferencia de que, en vez de usar corbata, tenía una colección de corbatines que combinaba cada día de la semana.

Hugo Salazar era un mulato elegante, alto y espigado, que comenzó a tener un aprecio especial entre sus alumnos por la forma cómo dictaba El Quijote, la poesía de origen Árabe y la poesía Latinoamericana. El profesor, en vez de hacer una exposición formal sobre Cervantes, el poema de origen árabe "Abenámar", los "Poemas humanos" de César Vallejo o la poesía negra del cubano Nicolás Guillén, sacaba a relucir sus capacidades histriónicas, y los interpretaba en clase. Era un performance rítmico y sincopado que seducía hasta el más lento de la clase; una especie de poéticapedagógica que rompía con los moldes de la escolástica tradicional tan en boga por aquellos años. ¿De dónde venía esa inventiva histriónica y musical? ¿De dónde provenía esa pedagogía kinética y polirrítmica?

Indudablemente venía de sus raíces negras, de Condoto, su pueblo natal, situado en el departamento del Chocó, en Colombia, una región que se caracteriza por tener la más alta tasa de la población de origen afrodescendiente del país. Luego, cuando comencé a interesarme por su vida y su obra, me di cuenta que Hugo Salazar Valdés, en su errancia intermitente por las poblaciones del sur del país; valga decir, Cali, Popayán, Pasto, Buga y Tulúa, se ganó la vida durante varios lustros declamando a los poetas hispanoamericanos.

El mundo de Hugo Salazar Valdés estuvo lleno de tribulaciones, que en aras a situarlo en el contexto de la poesía colombiana y latinoamericana, podríamos endilgárselas a dos hechos fundamentales que son claves en el destino de todo poeta: la región que lo vio nacer y la época que tuvo que vivir.

\section{El Chocó: aquel lugar donde comienza África.}

Salazar Valdés venía de una de las regiones más ricas, y al mismo tiempo, más olvidadas del país. El Chocó es una región, que por su ubicación geográfica ocupa una posición privilegiada en el continente suramericano. Al norte, limita con Panamá, al sur con el pie de monte de la cordillera Occidental de donde se desprenden los extensos valles del Cauca; al este con el pie de monte de la cordillera Central, y al oeste, con el andén del mar Pacífico que se extiende desde Punta Ardita en Panamá hasta las Bocas del río San Juan.

Desde el siglo XVI, el Chocó fue ruta de viajeros y conquistadores que venían en busca del Dorado. Por allí pasó Vasco Núñez de Balboa, que guiado por la india Anayanci, descubrió el Mar del Sur e intuyó por primera vez el canal de Panamá; por allí navegaron los conquistadores Juan de Ladrilleros y Pascual de Andagoya que fundaron el puerto de Buenaventura, por allí bajaron los 
hermanos Pizarro a conquistar el reino de los Incas. Las crónicas y relatos de Indias del siglo XVI dan cuenta de esta región selvática y enigmática, que originalmente fue ocupada por las tribus Cuevas, Cunas, Chocóes y Emberás, y que más tarde, ante el extermino de estas poblaciones aborígenes debido a las enfermedades, las guerras y las hambrunas, fueron reemplazadas por los esclavos africanos, para trabajar en las minas de oro y platino. Luego, en los siglos XVIII y XIX, los viajeros y científicos de la época como Alexander von Humboldt, Francisco José de Caldas, Charles Stuart Cochrane y Jean Baptiste Bousingault, entre otros, se refirieron en sus bitácoras de viaje a esta región del continente rica en su bio-diversidad, y que aún está por descubrir. El sabio Caldas supo definir muy bien esta región desde su óptica geofísica y metereológica:

Llueve la mayor parte del año. Ejércitos inmensos de nubes se lanzan en la atmósfera del seno del Océano Pacífico. El viento oeste que reina constantemente en estos mares, las arroja dentro del continente; los Andes las detienen en la mitad de su carrera. Aquí se acumulan y dan a esas montañas un aspecto sombrío y amenazador; el cielo desaparece; por todas partes no se ven sino nubes pesadas y negras que amenazan que amenazan a todo viviente. Una calma sofocante sobreviene, éste es el momento terrible; ráfagas de viento dislocadas arrancan árboles enormes; explosiones eléctricas, truenos espantosos; los ríos salen de su lecho; el mar se enfurece; olas inmensas vienen a estrellarse sobre las costas; el cielo se confunde con la tierra y todo parece que anuncia la ruina del universo. En medio de este conflicto el viajero palidece, mientras que el habitante del Chocó duerme tranquilo en el seno de su familia. Una larga experiencia le ha enseñado que los resultados de estas convulsiones de la naturaleza, son pocas veces funestos; que todo se reduce a luz, agua y ruido, y que dentro de pocas horas se restablecen el equilibrio y la serenidad.

En los albores de la República, el Chocó hizo parte geográfica y política del Estado soberano del Cauca junto a las regiones del Valle del Cauca, el Cauca y Nariño. Hasta esta fecha y debido a la explotación del oro y platino por parte de las compañía extranjeras, tuvo algún nivel de importancia para el país y para el mundo; pero luego, cuando las élites criollas se instalaron en el poder y comenzaron a gobernar bajo el imaginario euro-centrista, la región del Chocó así como las vastas y ricas tierras que no hacían parte de los Andes y del interior del país, fueron poco a poco olvidadas por los gobernantes. El imaginario euro-centrista asumido por las nuevas élites del país, no sólo contribuyó a consolidar una burguesía comercial e industrial en pleno ascenso, sino que rompió con los vínculos profundos interregionales que mal que bien existieron hasta el siglo XVIII produciendo una política de aislamiento y segregación, sobre todo, con las poblaciones indígenas y negras.

La Constitución de 1886, que se erigió como centralista, católica, apostólica y romana, y que nos gobernó durante una centuria, iba a reproducir esta disfuncionalidad entre el centro y la periferia, entre la capital y las provincias, dejando aislada a una región tan rica y llena de porvenir como era 
el Chocó. A este odioso aislamiento se sumaron las dificultades de origen topográfico que siempre han existido en Colombia y América latina y que han repercutido, para mal, en las necesarias comunicaciones entre los países y sus regiones.

Después de la Constitución del 86, y más tarde, de la separación del país político en Departamentos, llevada a cabo en 1910 (donde la región chocoana quedó aislada por Decreto de sus regiones vecinas, Valle, Cauca y Nariño), el Chocó que se constituyó en Departamento tardíamente, en el año de 1947, pasó del auge a la decadencia; del interés de los viajeros consignado en sus crónicas y relatos de viaje, al olvido. Amén de la corrupción de sus políticos venales que lo han esquilmado a más no poder.

Sólo es a partir de la década del treinta, que el Chocó vuelve a ser tema de discusión en el Congreso de la República, a través de dos insignes hijos de esta tierra, que utilizando el estrado de la política vuelven a poner en el centro del debate a esta región ignorada por el gobierno central: me refiero a los parlamentarios Sofonías Yacup y Diego Luis Córdoba. El primero lo hizo a través a sus propuestas legislativas como parlamentario y quedaron consignadas en el libro canónico, Litoral recóndito publicado por primera vez en 1934. El libro es un interesante estudio socioeconómico del Chocó escrito desde el fondo de sus raíces. El segundo personaje importante de esta época fue el Congresista liberal Diego Luis Córboba quien propició la creación del Departamento y fue un defensor de los derechos humanos y las minorías negras.

\section{El poeta del Chocó}

Las décadas del treinta y cuarenta son, justamente, el periodo de formación y juventud del poeta Hugo Salazar Valdés. Una época signada por las ideas liberales del país; pero así mismo, determinada por un país dependiente y atrasado que iba larvando en su interior el signo fatídico de la violencia, producto de las desigualdades sociales y de las exclusiones regionales y raciales.

El joven poeta de Condoto le toca vivir este estado de cosas, y ante las escasas posibilidades culturales que le brinda una pequeña ciudad minera y tropical, como es su ciudad natal, decide vagabundear por las ciudades del sur del país y anclar, finalmente, en Popayán, la antigua capital del Estado del Cauca, donde realiza sus estudios literarios y se nutre de la atmósfera literaria reinante de la época. Allí recibe el influjo de la poesía colombiana, que en esos momentos descansaba en las voces del "piedracielismo" quienes a través de la poesía, buscaban la perfección en las formas en detrimento de la simbología poética.

De esa necesaria pero desafortunada influencia, son sus Sonetos Talíacos inspirados en Eduardo Carranza, donde el verso es perfecto y la presencia de la amada ausente figura en medio de ensoñaciones metafísicas. 
Asomas al balcón de tu sonrisa

La luz que guardas infantil y bella

Y aminoras el brillo de la estrella

Y la suave frescura de la brisa.

Así comienza el "Soneto número uno”. En el "Soneto número siete, leemos:

Amo el azul que ignora tus enojos

y es por ello el zafiro que procuro

y el marinero de belleza puro

peregrino en las islas de tus ojos.

Como se puede apreciar, aquí la preocupación del poeta no consiste en ahondar en el verso profundo sino que, siendo fiel a la Gramática de la lengua, le interesa pulir un verso consonante para así alcanzar la perfección del lenguaje poético. Por supuesto, en un país aislado culturalmente como fue Colombia, y que no tuvo vanguardias poéticas y literarias durante la primera mitad del siglo XX, éste era el estilo poético que se estilaba en las tertulias bogotanas y payanesas de la época. El joven Hugo Salazar, quien venía del litoral recóndito -para que aquí usemos la expresión de Yacup-, es decir, quien provenía de la provincia olvidada e ignorada, no podía hacer otra cosa en aquellos oscuros años que mimetizarse en el discurso poético del establecimiento para legitimarse como poeta. En un país conservador como ha sido el nuestro, el verso consonante y cacofónico estaba a la orden del día. Pero no sólo él fue el poeta del Chocó quien cayó en la trampa de los gramáticos de la lengua. Todos, desde Rafael Maya hasta Carlos Martín, desde Jorge Rojas hasta Arturo Camacho Ramírez, siempre quisieron imitar el poema perfecto y bobalicón que nació en las tertulias bogotanas y fue aplaudido por los diferentes gobiernos reaccionarios que se sucedieron durante la primera mitad del siglo XX. Quizás, dentro del panorama de la poesía colombiana, los únicos poetas que se salvaron de la metáfora chata y el retruécano altisonante fueron León de Greiff, Aurelio Arturo y Luis Carlos López. De Greiff, porque su poesía era ritmo, música y venía de culturas lejanas; Arturo, porque fue fiel al paisaje que lo vio nacer; y el "Tuerto" López, porque le cantó con humor y desparpajo a su pequeña ciudad.

De resto, el grueso de la poetas, incluyendo a Hugo Salazar Valdés en su primera etapa literaria, fue víctima de una poética anacrónica, que nunca supo ni se interesó por la existencia del creacionismo, el surrealismo, el dadaísmo y las vanguardias.

La primera etapa en la poesía de Hugo Salazar Valdés tiene un carácter mimético. En su afán por buscar su identidad poética, el joven escritor toma prestado el legado añejo y conservador de la 
poesía colombiana, que después de Neruda, Huidobro y Vallejo, se había detenido en el tiempo y le seguía cantando a los camellos, a los leones y a los cisnes, en un país donde no hay camellos ni leones ni cisnes, y en cambio, proliferaban los micos, los lagartos y los sapos.

La búsqueda de la identidad poética en Hugo Salazar Valdés hacía parte de la búsqueda de su identidad como afrodescendiente. Por esto, y desde muy temprano, intuye que el modelo "Piedracielista" no es lo suyo, no es el tono de su poesía; no representa la poética que le interesa expresar; y rápidamente, como un hombre que ha nacido rodeado de mar y selva, comienza a encontrarse con su mundo, en las "Once elegías", que escribió a lo largo de su vida.

En la Elegía suplicante vamos a encontrar esta bella estrofa, que escrita en verso libre comenzará a romper con las ataduras del lenguaje y a vislumbrarse el universo marino que lo llevó consigo hasta el final de sus días:

Dame la paz de tu bahía

para el final de mis oficios, que voy a anclar mi corazón en el silencio de tu olvido.

En la Elegía azul dice:

El bello Sur que amara tu delicado rostro le confirió el encanto de despertar mi voz; orto y poniente suman gemelas geografías y en el símbolo gime la sed de mi canción.

En estas dos estrofas, el poeta encuentra las primeras claves de su poesía que lo llevara a inventar un universo poético único y singular: el mundo marino y selvático con sus negros y negras ancestrales traídas a la fuerza desde África. Mundo que lo distancia poéticamente del centro para convertirse en un poeta ex - céntrico que lo emparenta directamente con la poesía afrodescendiente inaugurada en el continente americano por el colombiano Candelario Obeso, el cubano Nicolás Guillén y el puertorriqueño Luis Palés Matos. Mundo que hace parte de su identidad como ser humano y como afrodescendiente. Mundo que servirá de rito de pasaje entre la invisibilidad del negro y el universo de lo visible. Mundo que lo perseguirá hasta el final de sus días y que no lo abandonará sino hasta el día de su muerte.

En su poema Dimensión de la tierra, leemos:

Porque al norte comienza el cautiverio

Sangra mi voz con Acandí en la arena

honda de peces, de tinieblas y ángeles.

¡Allí empieza la selva! ¡La ancha selva!

Poligramas 35, primer semestre 2011, ISSN 0120-4130. 
que devora, que atrapa, que acribilla, descomunal, satánica, sin tiempo, en hoguera de sola lengua verde!

\section{$(\ldots)$}

La selva en donde Dios se perdería de misterios sinnúmero y caídas. La presencia del monstruo, la zozobra, la entraña del abismo, las ficciones, la fiebre vegetal con ojos ásperos, la luz crucificada, la tormenta.

En El mar bifronte, leemos:

¡Este es el mar: acuático delirio!

¡Cementerio de ríos suicidas que se buscan!

¡Lámpara torrencial de espumosos sollozos!

Viejo solar brumoso de obreras lejanías su barba de sal sabe circunvalar la tierra; es amistoso abismo con sus hombros veleros y su esplendor bilingüe de orfebre y hortelano.

Selva y mar. Mar y selva. Dos figuras toponímicas que han sido constantes en la poesía negra de América, y que lo emparenta con su compatriota, el guapireño Helcías Martán Góngora.

En las Once elegías no podríamos dejar pasar por alto dos poemas: la Elegía dedicada a Rocinante, el caballo y compañero fiel del Quijote, quien pasó a la historia no sólo por la obra magna de la literatura universal sino también porque desde que fue inventado por Cervantes en el año 1600, no deja de recibir honores literarios. Como ya lo he dicho, Salazar Valdés fue un hombre que siempre volvía a la lectura del Quijote y lo hacía con el goce de encontrar en la obra clásica escrita en lengua española, las claves secretas de la humanidad. Seguramente, porque en su trajinar por su vida, él, de alguna manera era un Quijote, se sentía un Quijote.

El orbe aplaude el ideal y avío

de tu loco señor y su escudero

y olvida tu pavesa de lucero

cual si no hubieras encarnado el brío.

\section{$(\ldots)$}


Sin ti don Quijote muerto habría

Sancho flor de sustancia no sería

Ni Miguel iniciara el alfabeto.

Afirma en esta bella y sabia Elegía.

La segunda lamentación poética es la que le dedica al poeta peruano César Vallejo de quien también sentía que tenía muchas afinidades:

Tú también anduviste muriéndote por dentro como los condenados a su propio exterminio y tu calvario era la oscuridad reinante de la hiel, y el destino de la tristeza siempre.

$$
(\ldots)
$$

El callado pesar del pan escaso y duro

y el ajeno café que tu mal consumía

cifran el recio puño en que te vio Picasso

arenoso en tu verso de cardos amarillos.

Pero es en los poemas "Baila negro", "La negra María Teresa" e "Historia de Mary Bann" donde el poeta, después de beber de los vasos comunicantes dados por la cultura de Occidente, vuelve a su origen, a sus raíces de negro-mulato y transterrado, y le canta a su raza, ya no con el sufrimiento que imponía la rigidez del lenguaje de los gramáticos de la lengua, sino con la libertad que impone el lenguaje rítmico y sincopado de los pueblos afro-americanos:

Tin tan, tin tan., tin tan suena el timbal;

porongo, oblongo, marongo;

ronca el bongó;

gime la flauta,

ruge el tambor

y entre los "chasquis"

de las maracas

va el lagrimón.

Aquí, en este bello poema, es inevitable el "aire de familia" con Los cantos de mi tierra del escritor colombiano Candelario Obeso, Motivos de son del escritor cubano Nicolás Guillén y Tuntún de pasa y grifería del escritor puertorriqueño Luis Palés Matos. 
En el poema "La negra María Teresa" se produce la comunión del poeta con la mujer negra, resaltando su identidad africana y su belleza singular:

Oscura, de tinta china,

era la María teresa.

Pupilas de lumbre mora, piel de betún y brea, sonrisa de caña dulce su boca de miel de abejas y las manos como dos guillotinadotas negras.

En La historia de Mary Bann aparece el dios Eros, que a través del baile y la música de origen africano, revive el sortilegio del negro con la rubia:

Fue en un amanecer de libaciones

con marineros y guitarras, marimbas y tambores.

Deseada fruta de solar extraño

Mary Bann se llamaba

la rumba florecía el embrujo

de sus caderas libertinas

que en ágiles cadencias

prendía hogueras de soles antillanos.

El poeta también le cantó a las ciudades del Pacífico Sur que lo escucharon cuando iba por sus bares declamando a Luis de Góngora y Argote, César Vallejo y Nicolás Guillén, sus poetas preferidos.

A Cali la llamó "novia del valle"; a Popayán "silenciosa en su oficio de diamante"; de Quibdó dijo que la "enalban dulces aves y flores que deslumbran"; a Buga la nombró "bella en su mansedumbre religiosa"; a Pasto "amada flor sin sombras ni quebranto"; y a Condoto, el lugar donde nació, "amorosa colmena de fraternal jornada".

En su poesía también le dejó espacio a la isla de San Andrés para, de esta manera, reestablecer el puente cultural, que en otros tiempos se hizo a través del río Atrato, entre los dos grandes mares que bañan nuestra geografía: el mar Pacífico y el mar Caribe.

¡Fábula verde de galán océano!

$¡$ ¡Tu ensimismado caracol

Poligramas 35, primer semestre 2011, ISSN 0120-4130. 
iza la voz del viento y las mareas

Isla asesora de la poesía!

La presente Antología, que hoy publica el Ministerio de Cultura de Colombia, fue realizada por el poeta Hugo Salazar Valdés, un poco antes de su muerte, acaecida en Cali, en 1977. La selección, que él mismo tituló con el nombre de Antología íntima, es una revisión minuciosa y crítica que hizo el bardo, como una manera de dejarle a los lectores, las mejores flores poéticas, producidas por él, a lo largo de su vida.

Para este inventario literario, Hugo Salazar Valdés tuvo en cuenta sus primeros poemarios publicados a finales de las décadas del cuarenta y cincuenta, como son: Sol y lluvia, Carbones en el alba, Dimensión de la tierra, Casi la luz, La patria convocada, El héroe cantado y Toda la voz. Así mismo, sus libros más recientes, publicados en la década del setenta: Pleamar y Poemas amorosos. En su testamento literario, rescatado por Vicente Pérez Silva, y que se puede leer en la página virtual de la Biblioteca Luis Ángel Arango, el poeta escribe, a propósito de su selección crítica:

De mis precipitadas publicaciones he revisado y corregido los poemas que componen esta antología, y, como lo he hecho ante mí y para mí, agradeceré al posible lector que por alguna circunstancia desee referirse a mis escritos, hacerlo afirmándose preferentemente en los textos que aparecen aquí.

Hugo Salazar Valdés pasó sus últimos años de su vida en Cali. De su obra, hablaron Rogelio Echavarría, Jaime Mejía Duque, Vicente Pérez Silva, Fernando Ayala Poveda, Hortensia Alaix de Valencia, Alfonso Martán Bonilla, Julián Malatesta y Alain Lawo-Sukam. El poeta del Chocó jamás se preocupó si la crítica en Bogotá lo incluía o no en las famosas Antologías de poesía colombiana. Tampoco se interesó por pertenecer a capillas o círculos literarios. En el fondo, era un hombre solitario que cuando se jubiló del Magisterio le gustaba pasearse por las calles calientes de la ciudad con su vestido entero, impecable, y su lujoso artefacto rojo que se colocaba a la altura del cuello.

\section{Bibliografía}

Alaix de Valencia, Hortensia. La palabra poética del afro-colombiano. Cali, Litocencoa, 2003

Echavarria, Rogelio. Antología de la poesía colombiana. Áncora Editores, Bogotá, 1997

Lawo-Sukam, Alain. Hacia una poética afro-colombiana: El caso Pacífico. Editorial facultad de Humanidades, Univalle, Cali, enero 2010

Martinez, Fabio. Balboa, el polizón del Pacífico. Editorial Norma, Bogotá, 2007 
Navarrete, María Cristina. Génesis y desarrollo de la Esclavitud en Colombia: siglos XVI y XVII. Programa Editorial Univalle, Cali, 2005

Salazar Valdés, Hugo. Carbones en el alba. Editorial Iqueima, Bogotá, 1948 Casi la luz. Editorial Cosmos, Bogotá, 1954 Pleamar. Imprenta Departamental, Cali, 1975 Poemas amorosos. Imprenta Departamental, Cali, 1976 Rostro iluminado del Chocó. Editorial Feriva, Cali, 1980 Antología íntima. Colección de poesía Escala de Jacob. Universidad del Valle, Facultad de Humanidades, Cali, 2005 Yacup, Sofonías. Litoral recóndito. Ediciones Drake, Medellín, 1993. 